\title{
PENGARUH OUTDOOR EDUCATION TERHADAP KEPERCAYAAN DIRI SISWA DALAM EKSTRAKURIKULER
}

\author{
Dicky Oktora Mudzakir'1, Mochamad Zakky Mubarok ${ }^{2}$ \\ 1, 2Program Studi Pendidikan Jasmani Kesehatan dan Rekreasi, \\ STKIP Nahdlatul Ulama Indramayu, Jln. Raya Kaplongan No. 28 Indramayu, Jawa Barat \\ 1e-mail: dicky_oktora@stkipnu.ac.id
}

\begin{abstract}
Abstrak
Penelitian ini bertujuan untuk menguji perbedaan pengaruh sebelum dan sesudah diberikan outdoor education terhadap kepercayaan diri siswa SMK. Metode penelitian menggunakan pre eksperimen dengan one-group pretest-posttest design. Partisipan dalam penelitian ini sebanyak 20 siswa yang mengikuti kegiatan ekstrakurikuler dengan menggunakan sampling sistematis. Instrumen dalam penelitian ini menggunakan angket kepercayaan diri. Analisis data dengan menggunakan paired samples t-test. Hasil penelitian membuktikan terdapat perbedaan pengaruh sebelum dan sesudah diberikan outdoor education terhadap kepercayaan diri siswa SMK.
\end{abstract}

Kata kunci: kepercayaan diri, outdoor education, ekstrakurikuler

\begin{abstract}
This study is intended to discuss the differences before and after being given outdoor education to the confidence of vocational students. The research method uses preexperiments with the design of one group pretest-posttest. Participants in this study were 20 students who took extracurricular activities using integrated sampling. The instrument in this study used a self-confidence questionnaire. Data analysis using paired samples t-test. The results of the study prove the existence of differences before and given outdoor education to the confidence of vocational students.
\end{abstract}

Keywords: self confidence, outdoor educatio, extracurricular

\section{PENDAHULUAN}

Ekstrakurikuler adalah kegiatan kurikuler yang dilakukan oleh peserta didik di luar jam belajar kegiatan intrakurikuler dan kegiatan kokurikuler, di bawah bimbingan dan pengawasan satuan pendidikan (Permendikbud, 2014). Kegiatan ekstrakurikuler terdiri dari ekstrakurikuler wajib dan ekstrakurikuler pilihan (Permendikbud, 2014). Di Indonesia kegiatan ekstrakulikuler merupakan salah satu isu yang terus berkembang (Ginanjar, 2015; Ginanjar, Suherman, Juliantine, dan Hidayat, 2019). Ini berbanding terbalik dengan tujuan dari ekstrakurikuler yang diselenggarakan. Kegiatan ekstrakurikuler di sekolah masih belum signifikan dampaknya bagi pengembangan peserta didik (Lestari, 2016). Diharapkan ekstrakulikuler sebagai pengembangan potensi peserta didik sebagaimana dimaksud dalam tujuan pendidikan nasional dan dapat memfasilitasi 
pengembangan potensi peserta didik melalui pengembangan bakat, minat, dan kreativitas serta kemampuan berkomunikasi dan bekerja sama dengan orang lain.

Kepercayaan diri adalah salah satu masalah yang dihadapi siswa, sehingga mengakibatkan kehilangan keyakinan atau rasa optimis dalam menghadapi tantangan yang akan mereka dapat. Sering kita melihat seorang siswa yang mampu melakukan gerakan yang ditugaskan tetapi dia malah takut atau tidak serius melakukan gerakan karena kurang memiliki kepercayaan diri (Ginanjar, 2016). Padahal, kepercayaan diri merupakan perantara antara hubungan motivasi dan keberhasilan yang dapat dirasakan (Ibrahim, Jaafar, Kassim, dan Isa, 2016). Oleh sebab itu kepercayaan diri merupakan salah satu faktor pendukung siswa dalam menjalani kehidupan mereka sehari-hari agar mendapatkan keberhasilan dalam menjalani kehidupannya.

Kepercayaan diri terdiri dari dua jenis yaitu qualities of inner confidence dan skills of outer confidence (Lindenfield, 1995), lebih lanjut yaitu kepercayaan diri batin dan lahir (Lindenfield, 1997). Kepercayaan diri batin berkaitan dengan percaya diri yang dimiliki dari dalam diri orang tersebut yang terdiri dari cinta diri, pemahaman diri, tujuan yang jelas, dan berfikir positif. Sedangkan kepercayaan diri lahir berasal dari kesan pada dunia luar yang terdiri dari komunikasi, ketegasan, penampilan diri, dan pengendalian diri.

Berkaitan dengan aspek kepercayaan diri batin menurut Lindenfield (1995) terdiri dari: 1) cinta diri berkaitan dengan memelihara diri sendiri, jadi sesorang yang memiliki kepercayaan diri akan memiliki gaya hidup yang memperdulikan diri mereka sendiri. 2) Pemahaman diri berkaitan dengan seseorang yang sadar dengan potensi yang dimiliki, orang yang dapat memahami dirinya sendiri memungkinkan dia akan melakukan kesalahan yang berulang-ulang, tidak mengikuti orang lain, memiliki sahabat yang mengerti dirinya, dan dapat merima krtitik dan bantuan. 3) Tujuan yang jelas berkaitan dengan orang yang mempunyai tujuan dalam hidupnya, memiliki motivasi, dan mampu untuk membuat keputusan dalam pemenuhan keinginan dalam mencapai hasil dari tujuan yang telah ditetapkan. 4) Berfikir positif berkaitan dengan seseorang yang selalu memiliki 
harapan dalam menjalani hidup, memiliki motivasi dalam menjalankan hidup, dan memiliki rasa kepercayaan bahwa segalam masalah dapat dia atasi.

Sedangkan dalam aspek kepercayaan diri lahir menurut Lindenfield (1995) terdiri dari empat aspek juga yaitu: 1) Komunikasi berkaitan dengan seseorang yang dapat mendengarkan orang lain, tenang, penuh perhatian, dapat berdialog dengan semua orang dari berbagai latar belakang, mampu mengatur dialog dari percakapan yang santai kepada percakapan yang serius, dan mampu untuk berbicara di depan umum tanpa rasa gelisah. 2) Ketegasan berkaitan dengan sesorang yang memiliki sifat tegas yang tidak menunjukan sikap agresif dan pasif dalam pencapaian kesuksesan hidup dan interaksi secara sosial. 3) Penampilan diri berkaitan dengan seseorang yang dapat bergaul dengan orang lain dengan apa adanya, sopan, berpenampilan menarik sehingga telihat kesan seseorang yang penuh tampil percaya diri. 4) Pengendalian diri berkaitan dengan keberanian seseorang dalam menghadapai berbagai macam masalah, tantangan, dam tidak mudah tersulut emosi.

Berkaitan dengan masih adanya masalah kepercayaan diri siswa, kegiatan ekstrakurikuler dapat dijadikan salah satu kegiatan dalam pengembangan potensi siswa. Maka, diperlukan program yang dapat meningkatakan kepercayaan diri siswa. Salah satu kegiatan yang dapat digunakan ialah program outdoor education. Beberapa pakar education outdoor berpendapat bahwa pendidikan yang berberlanjutan adalah tujuan utama dari pembelajaran outdoor education (Cachelin, Rose, dan Dustin, 2011; Prince, 2016). Lebih lanjut lagi, kontribusi prioritas lintas kurikulum yang berkelanjutan mungkin menjadi masa depan yang penting bagi outdoor education di sekolah-sekolah karena para pendidik outdoor membangun hubungan lintas-disiplin yang mengeksplorasi pengalaman pribadi langsung di dunia alami untuk mengembangkan perilaku pro-lingkungan yang berkelanjutan hingga dewasa (Cachelin et al., 2011; Prince, 2016). Oleh karena itu dengan program outdoor education dapat digunakan sebagai salah satu program yang dapat membantu siswa menjalani kehidupan sehari-harinya. Outdoor education menghasilkan peluang yang lebih besar untuk sukses dalam kegiatan sehari-hari (Yıldız, Özen, dan Bostanc1, 2016), yang mana dalam menjalani 
kehidupan sehari-hari salah satu faktor pendukung dalam pencapaian keberhasilan hidup dengan adanya kepercayaan diri.

Dalam penelitian ini peneliti melakukan kegiatan dengan menggunakan program outdoor education yang di dalam kegiatannya menggunakan bentuk permainan Outward Bound. Kursus Outward Bound dirancang untuk mengembangkan pemahaman seorang anak muda tentang kemampuan mereka (Outwardbound.org.uk, 2017). Secara umum, program ini bertujuan untuk menghasilkan perubahan positif pada siswa dengan rencangan program, sehingga dapat mendorong siswa untuk pemenuhan penemuan diri dan pembentukan karakter siswa itu sendiri. Perubahan mungkin termasuk harga diri, sikap sosial, kepemimpinan, keterampilan pemecahan masalah, kohesi tim dan perilaku (Cason \& Gillis, 1994).

Program outdoor education yang digunakan digabungkan dengan bentuk kegiatan fisik dalam outward bound. Kegiatan fisik outward bound yang diberikan lebih kepada arah tanggung jawab kerjasama tim. Ini berkaitan dengan keterampilan fisik yang diajarkan sebagai cara mendorong peserta secara berkelompok yang dihadapkan pada situasi menantang yang menuntut kearah memenuhi upaya, tekad, kerjasama, kemandirian, dan semua peserta mengambil tanggungjawab untuk semua aspek (Wang, Liu, \& Kahlid, 2006). Lebih lanjut, tantangan yang diberikan oleh instruktur kepada siswa direncanakan dan dikelola dengan cermat sehingga setiap individu didorong untuk menghadapi sesuatu yang belum pernah mereka lakukan sebelumnya (Outwardbound.org.uk, 2017).

Kekhawatiran yang semakin besar tentang menurunnya kesempatan untuk outdoor education menjadi sebuah permasalahan. Kurikulum tanpa sadar telah mengikis outdoor education yang mengatakan tampaknya bukan pilihan yang sehat untuk pertumbuhan dan kelangsungan outdoor education di sekolah (Dillon et al., 2005). Padahal program outdoor education telah berkembang pesat dalam berbagai penelitian. Sejumlah efek positif pada pengembangan pribadi dan sosial, aktivitas fisik, prestasi akademik, dan keterampilan kepemimpinan untuk berbagai peserta dan kelompok umur (Becker, Lauterbach, Spengler, Dettweiler, \& Mess, 2017; Waite, Bølling, \& Bentsen, 2015). Dalam outdoor education pada dimensi 
sosial, siswa mendapat manfaat dalam hal pengembangan kompetensi sosial dan hubungan sosial mereka seperti harga diri, kepercayaan diri, hubungan saling percaya, dan rasa memiliki (Hartmeyer \& Mygind, 2016; Sharpe, 2014; Wistoft, 2013). Lebih khusus lagi, salah satu siswa telah meningkat secara besar-besaran dalam kepercayaan dirinya, sebelumnya siswa tersebut berjuang dengan rasa malu dan canggung tetapi dengan outward bound, sangat berharga untuk membantunya keluar dari kebiasaanya dan berbicara kepada orang-orang yang tidak dikenalnya (Outwardbound.org.uk, 2017).

Di Indonesia program outdoor education masih belum bisa diterapkan dalam proses intrakurikuler. Padahal berbagai hasil penelitian menyatakan program outdoor education memberikan pengalam pendidikan siswa, sikap sosial, tanggung jawab, aktivitas fisik, prestasi akademik, kepemimpinan, harga diri, saling percaya, kerjasama, rasa saling memiliki, dan kepercayaan diri yang menjadi bahasan di dalam penelitian ini. Dari dua jenis kepercayaan diri yaitu lahir dan batin akan dibahas di dalam penelitian, kepercayaan diri manakah yang dapat lebih mempengaruhi kepercayaan diri siswa dalam mengikuti program outdoor education. Peneliti ini ingin memberikan gambaran bagaimana program outdoor education dimasukan ke dalam ektrakurikuler yang diharapakan hasil penelitian ini dapat menjadi salah satu rujukan program outdoor education dapat diimplementasikan ke dalam kegitan intrakurikuler. Dari keseluruhan pemaparan di atas, maka tujuan dari penelitian ini untuk menguji perbedaan pengaruh sebelum dan sesudah diberikan outdoor education terhadap kepercayaan diri siswa SMK.

\section{METODE}

Metode penelitian di dalam penelitian ini dengan menggunakan metode pre eksperimen dengan one-group pretest-posttest design, jadi terdapat suatu kelas diberi pretest kemudian treatment lalu diberikan posttest sehingga hasil perlakuan lebih akurat dengan membandingkan keadaan sebelum diberikan perlakuan. Partisipan dalam penelitian ini berasal dari populasi sebanyak 118 siswa SMK NU Kaplongan Indramayu yang mengikuti kegiatan ekstrakurikuler, partisipan 
diambil dengan menggunakan sampling sistematis yang diambil pada kelipatan enam sehingga didapat partisipan sebanyak 20 orang.

Tabel 1 Program Outdoor Education

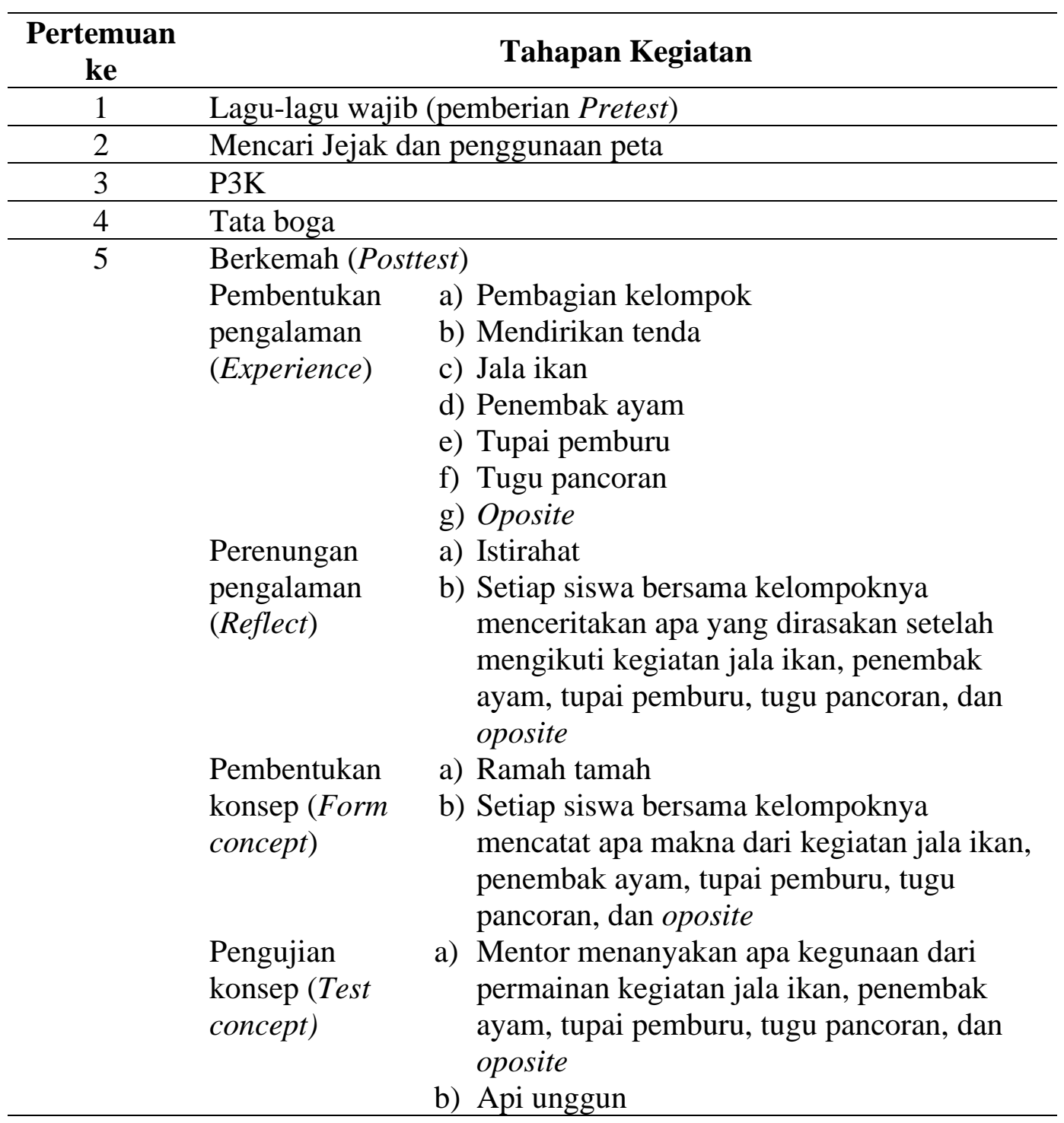

Teknik pengukuran data dengan menggunakan tes. Instrumen tes yang digunakan untuk mengukur kepercayaan diri siswa menggunakan angket kepercayaan diri yang telah dilakukan validasi dengan jumlah 40 item tes sebanyak 26 item tes dinyatakan valid dengan nilai reliabilitas sebesar 0.804 (Ginanjar, 2016). Dari angket tersebut peneliti mengadaptasi angket tersebut dengan merubah bentuk pertanyaan/ pernyataan ke dalam kegiatan program yang telah dilakukan dan melakukan kembali validasi kepada 52 orang. Hasil yang 
didapat dari 40 item tes sebanyak 31 item tes dinyatakan valid dengan nilai reliabilitas sebesar 0.940 yang dianalisis menggunakan cronbach alpha. Angket tersebut berasal dari aspek kepercayaan diri lahir dengan indikatornya: komunikasi, ketegasan, penampilan diri, dan pengendalian perasaan. Sedangkan aspek kepercayan diri batin dengan indikatornya: cinta diri, pemahaman diri, tujuan yang jelas, dan berfikir positif. Untuk kisi-kisi angket yang digunakan dapat di lihat pada Tabel 2.

Tabel 2 Kisi-Kisi Angket Kepercayaan Diri

\begin{tabular}{|c|c|c|c|c|c|c|}
\hline \multirow[t]{2}{*}{ Aspek } & \multirow[t]{2}{*}{ Indikator } & & \multirow[t]{2}{*}{ Sub Indikator } & \multicolumn{2}{|c|}{$\begin{array}{c}\text { Nomor } \\
\text { Item Tes }\end{array}$} & \multirow[t]{2}{*}{ Total } \\
\hline & & & & + & - & \\
\hline \multirow{11}{*}{$\begin{array}{l}\text { Kepercaya } \\
\text { an diri } \\
\text { batin }\end{array}$} & Cinta diri & 1) & $\begin{array}{l}\text { Mampu memelihara } \\
\text { dan memanfaatkan diri }\end{array}$ & 1,3 & 2 & 5 \\
\hline & & 2) & Memiliki sikap optimis & 4 & 5 & \\
\hline & $\begin{array}{l}\text { Pemahan } \\
\text { diri }\end{array}$ & 1) & $\begin{array}{l}\text { Mampu menyadari } \\
\text { kekuatan dan }\end{array}$ & 7 & 6,8 & 5 \\
\hline & & & kelemahan diri sendiri & 9 & 10 & \\
\hline & & 2) & $\begin{array}{l}\text { Mampu menerima } \\
\text { kritik baik positif atau } \\
\text { negatif dari orang lain } \\
\text { terhadap dirinya }\end{array}$ & & & \\
\hline & $\begin{array}{c}\text { Tujuan } \\
\text { yang jelas }\end{array}$ & 1) & $\begin{array}{l}\text { Memiliki target yang } \\
\text { harus dicapai dalam }\end{array}$ & 11 & 12 & 5 \\
\hline & & & belajar & 13,1 & 14 & \\
\hline & & 2) & $\begin{array}{l}\text { Dapat mengambil } \\
\text { keputusan dengan tepat }\end{array}$ & 5 & & \\
\hline & $\begin{array}{c}\text { Berfikir } \\
\text { positif }\end{array}$ & 1) & $\begin{array}{l}\text { Memiliki pandangan } \\
\text { yang positif terhadap }\end{array}$ & 16 & 17 & 5 \\
\hline & & & berbagai hal & 19 & 18,2 & \\
\hline & & 2) & $\begin{array}{l}\text { Dapat mensyukuri apa } \\
\text { yang di dapatnya. }\end{array}$ & & 0 & \\
\hline \multirow{7}{*}{$\begin{array}{l}\text { Kepercaya } \\
\text { an diri lahir }\end{array}$} & Komunikas & 1) & Mampu menyesuaikan & 21,2 & 22 & 5 \\
\hline & $\mathrm{i}$ & & diri dalam situasi & 3 & & \\
\hline & & & apapun & & 25 & \\
\hline & & 2) & $\begin{array}{l}\text { Mampu bersosialisasi } \\
\text { dan berinteraksi dengan } \\
\text { siapapun }\end{array}$ & 24 & & \\
\hline & Ketegasan & 1) & $\begin{array}{l}\text { Menyatakan kebutuhan } \\
\text { belajarnya secara terus }\end{array}$ & 27 & $\begin{array}{c}26,2 \\
8\end{array}$ & 5 \\
\hline & & & terang & 29 & & \\
\hline & & 2) & $\begin{array}{l}\text { Berani bertanya dan } \\
\text { menyatakan pendapat }\end{array}$ & & 30 & \\
\hline
\end{tabular}




\begin{tabular}{|c|c|c|c|c|c|c|}
\hline \multirow[t]{4}{*}{ Aspek } & \multirow[t]{2}{*}{ Indikator } & \multirow{2}{*}{\multicolumn{2}{|c|}{ Sub Indikator }} & \multicolumn{2}{|c|}{$\begin{array}{c}\text { Nomor } \\
\text { Item Tes }\end{array}$} & \multirow[t]{2}{*}{ Total } \\
\hline & & & & + & - & \\
\hline & $\begin{array}{c}\text { Penampila } \\
\text { n diri }\end{array}$ & $\begin{array}{l}\text { 1) } \\
\text { 2) }\end{array}$ & $\begin{array}{l}\text { Berpakaian lengkap } \\
\text { dan rapi } \\
\text { Selalu semangat } \\
\text { belajar walaupun } \\
\text { sedang memiliki } \\
\text { masalah }\end{array}$ & $\begin{array}{c}31 \\
33,3 \\
5\end{array}$ & $\begin{array}{l}32 \\
34\end{array}$ & 5 \\
\hline & $\begin{array}{l}\text { Pengendali } \\
\text { an diri }\end{array}$ & 2) & $\begin{array}{l}\text { Keberanian dalam } \\
\text { menghadapi tantangan } \\
\text { dan resiko yang akan } \\
\text { di dapat } \\
\text { Mampu } \\
\text { mengendalikan emosi }\end{array}$ & 36 & $\begin{array}{c}38,4 \\
0\end{array}$ & 5 \\
\hline \multicolumn{6}{|c|}{ Total item tes } & 40 \\
\hline
\end{tabular}

Teknik analisis data pada deskriptif statistik dihitung untuk mengetahui perbedaan rata-rata dan simpangan baku dari setiap data dengan bantuan aplikasi Statistical Package for the Social Sciences (SPSS). Uji normalitas untuk mengetahui apakah data tersebut berdistribusi normal atau tidak dianalisis menggunakan uji shapiro-wilk yang dianalisis dengan bantuan aplikasi SPSS. Untuk uji hipotesis untuk mengetahui perbedaan sebelum dan sesudah diberikan perlakuan dianalisis menggunakan paired samples t-test yang dianalisis dengan bantuan aplikasi SPSS.

\section{HASIL DAN PEMBAHASAN}

\section{Hasil}

Hasil analisis deskriptif statistik didapat hasil pretest dengan $=101.75$ dan $s=11.74$, pada hasil posttest dengan $\quad=119.65$ dan $s=11.74$. Uji normalitas pada hasil prestest didapat sebesar 0.104 dengan signifikansi $0.20>0.05$ dan hasil posttest didapat sebesar 0.172 dengan signifikansi $0.12>0.05$ maka kedua data tersebut berdistribusi normal. Uji hipotesis didapat $t_{\text {hitung }}=11.57$ dengan signifikansi $0.00<0.05$, maka terdapat perbedaan pengaruh outdoor education terhadap kepercayaan diri siswa SMK. 


\section{Pembahasan}

Fokus di dalam penelitian ini untuk menguji perbedaan pengaruh sebelum dan sesudah diberikan outdoor education terhadap kepercayaan diri siswa. Hasil penelitian menyatakan bahwa program outdoor education yang telah diberikan memberikan signifikansi terhadap kepercayaan diri siswa, sehingga terdapat perbedaan pengaruh sebelum dan sesudah diberikan outdoor education terhadap kepercayaan diri siswa.

Ini dapat disebabkan hasil program outdoor education yang diberikan dengan menggunakan bentuk permainan outward bound yan terdiri dari permainan jala ikan, penembak ayam, tupai pemburu, tugu pancoran, dan oposite. Untuk gambar kegiatan dapat di lihat pada Gambar 2. Pada permainan jala ikan, permainan ini didominasi gerakan untuk berlari, menghindar, melompat, bahkan berguling. Secara keseluruhan permainan ini bertujuan uintuk meningkatkan kerjasama, percaya kepada teman, saling membantu, kelincahan, kecepatan, saling interaksi satu sama lain, dan menciptakan strategi. Pada permainan penembak ayam, permainan ini didominasi gerakan melempar, menghindari lemparan, lari, lompat, bahkan berguling. Secara keseluruhan permainan ini memiliki tujuan yang sama dengan permainan jala ikan. Pada permainan tupai pemburu, permainan ini didominasigerakan berlari dan mengangkat. Secara keseluruhan permainan ini bertujuan uintuk menjaga konsentrasi, berfikir, bertindak cepat, bersosialisasi, dan kerjasama. Pada permainan tugu pancoran, permainan ini didominasigerakan berdansa, mendayung, melompat, dan berlari. Secara keseluruhan permainan ini bertujuan uintuk berfikir, bertindak cepat, dan bersosialisasi. Pada permainan opposite, permainan ini didominasigerakan melompat. Secara keseluruhan permainan ini bertujuan uintuk meningkatkan kerjasama,saling membantu, kelincahan, dan saling interaksi satu sama lain. 


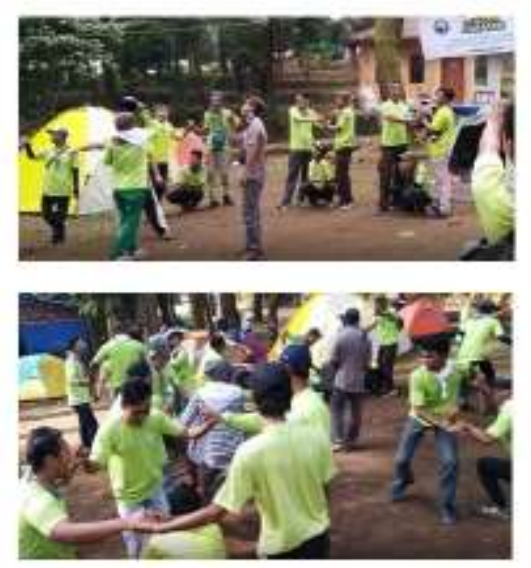

\section{Gambar 1 Kegiatan Outward Bound}

Penelitian ini memberikan dukungan dan sejalan dengan pernyataan bahwa dalam outdoor education pada dimensi sosial siswa tampaknya mendapat manfaat dalam hal pengembangan kompetensi salah satunya kepercayaan diri (Bowker \& Tearle, 2007; Ernst \& Stanek, 2006; Hartmeyer \& Mygind, 2016; Mygind, 2009; Sharpe, 2014; Wistoft, 2013). Hasil penelitian ini memberikan pandangan baru bahwa dalam kegiatan ekstrakurikuler dengan menggunakan program outdoor education yang dikombinasikan bentuk permainan outward bound dapat menjadi alternatif baru dalam peningkatan kepercayaan diri siswa.

Hasil penelitian ini menambah referensi bahwa outdoor education yang dikombinasikan bentuk permainan outward bound dapat dijadikan sebagai harapan dengan adanya kekhawatiran yang semakin besar tentang menurunnya kesempatan untuk outdoor education dalam pertumbuhan dan kelangsungan outdoor education di sekolah (Dillon et al., 2005). Outdoor education yang dikombinasikan bentuk permainan outward bound dan dirancang dengan baik dapat dijadikan alat untuk meningkatkan kepercayaan diri siswa. Selain itu, hasil penelitian ini diharapakan menjadi salah satu rujukan program outdoor education dapat diimplementasikan ke dalam kegaitan intrakurikuler khususnya dalam pendidikan jasmani. Hal ini berkaitan dengan pernyataan outdoor education berasal dari pendidikan jasmani. Secara historis outdoor education telah berada di bawah payung Health and Physical Education (Culpan, 2000; Gray \& Martin, 2012; Lugg, 1999; Zink \& Boyes, 2006). 


\section{SIMPULAN}

Hasil penelitian menyimpulkan bahwa terdapat perbedaan pengaruh sebelum dan sesudah diberikan outdoor education terhadap kepercayaan diri siswa SMK. Oleh karena itu, penelitian ini menyarankan agar melakukan penelitian lebih lanjut dengan menggunakan partisipan yang lebih banyak dan fokus kepada aspek-aspek dalam kepercayaan diri yang lebih spesifik agar hasil dan temuan yang didapat dalam penelitian ini dapat digeneralisasikan. Kemudian agar melakukan penelitian dalam intrakurikuler dan kokurikuler, kuhususnya dalam intrakurikuler pembelajaran pendidikan jasmani.

\section{DAFTAR PUSTAKA}

Becker, C., Lauterbach, G., Spengler, S., Dettweiler, U., \& Mess, F. (2017). Effects of regular classes in outdoor education settings: A systematic review on students' learning, social and health dimensions. International Journal of Environmental Research and Public Health, 14(485), 1-20. (Online), (https://doi.org/10.3390/ijerph14050485).

Bowker, R., \& Tearle, P. (2007). Gardening as a learning environment: A study of children's perceptions and understanding of school gardens as part of an international project. Learning Environments Research, 10, 83-100. (Online), (https://doi.org/10.1007/s10984-007-9025-0).

Cachelin, A., Rose, J., \& Dustin, D. (2011). Sustainability in outdoor education: rethinking root metaphors. Journal of sustainability education, 2.

Cason, D., \& Gillis, H. L. "Lee." (1994). A meta-analysis of outdoor adventure programming with adolescents. The journal of experiential education, 17(1), 40-47. (Online), (https://doi.org/10.1177/105382599401700109).

Culpan, I. (2000). Getting what you got: harnessing the potential. Journal of physical education new zealand, 33(2), 16-30.

Dillon, J., Morris, M., O`Donnell, L., Reid, A., Rickinson, M., \& Scott, W. (2005). Engaging and learning with the outdoors - the final report of the outdoor classroom in a rural context action research project. Slough: National Foundation for Education Research.

Ernst, J., \& Stanek, D. (2006). The prairie science class: A model for re-visioning environmental education within the national wildlife refuge system. Human Dimensions of Wildlife, 11(4), 255-265. (Online), (https://doi.org/10.1080/10871200600803010).

Ginanjar, A. (2015). The influence of inquiry method in motivating the smp' student. Jurnal kependidikan, 45(2), 123-129. (Online), (https://doi.org/http://dx.doi.org/10.21831/jk.v45i2.7489).

Ginanjar, A. (2016). Hasil belajar pendidikan jasmani: disiplin motivasi dan percaya diri. MAENPO, VI, 88-96.

Ginanjar, A., Suherman, A., Juliantine, T., \& Hidayat, Y. (2019). Sports 
orientation during learning team or individual sports using a sport education model. Cakrawala pendidikan, 38(2), 377-386. (Online), (https://doi.org/10.21831/cp.v38i2.24021).

Gray, T., \& Martin, P. (2012). The role and place of outdoor education in the Australian National Curriculum. Australian journal of outdoor education, 16(1), 39-50. (Online), (https://doi.org/10.1007/bf03400937).

Hartmeyer, R., \& Mygind, E. (2016). A retrospective study of social relations in a Danish primary school class taught in 'udeskole.' Journal of adventure education and outdoor learning, 16(1), 78-89. (Online), (https://doi.org/10.1080/14729679.2015.1086659).

Ibrahim, H. I., Jaafar, A. H., Kassim, M. A. M., \& Isa, A. (2016). Motivational climate, self-confidence and perceived success among student athletes. Procedia economics and finance, 35, 503-508. (Online), (https://doi.org/10.1016/s2212-5671(16)00062-9).

Lestari, R. Y. (2016). Peran kegiatan ekstrakurikuler dalam mengembangkan watak kewarganegaraan peserta didik. Untirta civic education journal, 1(2), 136-152. (Online), (https://doi.org/10.30870/ucej.v1i2.1887).

Lindenfield, G. (1995). Super confidence at work. Executive Development, 8(1), 9-11. (Online), (https://doi.org/10.1108/09533239510079491).

Lindenfield, G. (1997). Mendidik anak agar percaya diri: pedoman orang tua. In Arcan. Jakarta: Arcan.

Lugg, A. (1999). Directions in outdoor education curriculum. Australian journal of outdoor education, 4(1), 25-32. (Online), (https://doi.org/10.1007/bf03400706).

Mygind, E. (2009). A comparison of childrens' statements about social relations and teaching in the classroom and in the outdoor environment. Journal of adventure education \& outdoor learning, 9(2), 151-169. (Online), (https://doi.org/10.1080/14729670902860809).

Outwardbound.org.uk. (2017). Young people who are more confident and who self-confidence ( rather than people or events controlling them ), then they (Online), (https://www.outwardbound.org.uk/assets/pdf/uploads/Impact/confidentin-themselves.pdf, diakses 2 November 2019).

Permendikbud. (2014). Kegiatan ekstrakurikuler pada pendidikan dasar dan pendidikan menengah. Jakarta: Kementerian Pendidikan dan Kebudayaan.

Prince, H. E. (2016). Outdoor experiences and sustainability. Journal of adventure education and outdoor learning, 17(2), 161-171. (Online), (https://doi.org/10.1080/14729679.2016.1244645).

Sharpe, D. (2014). Independent thinkers and learners: a critical evaluation of the 'growing together schools programme.' Pastoral care in education, 32(3), 197-207. (Online), (https://doi.org/10.1080/02643944.2014.940551).

Waite, S., Bølling, M., \& Bentsen, P. (2015). Comparing apples and pears?: a conceptual framework for understanding forms of outdoor learning through comparison of English Forest Schools and Danish udeskole. Environmental education research, 1-25. (Online), (https://doi.org/10.1080/13504622.2015.1075193). 
Wang, C. K. J., Liu, W.-C., \& Kahlid, A. (2006). Effects of a five-day Outward Bound course on female students in Singapore. Australian journal of outdoor education, 10(2), 20-28. (Online), (https://doi.org/10.1007/bf03400836).

Wistoft, K. (2013). The desire to learn as a kind of love: gardening, cooking, and passion in outdoor education. Journal of adventure education and outdoor learning, $13(2)$, $125-141$.

(Online), (https://doi.org/10.1080/14729679.2012.738011).

Y1ld1z, N. O., Özen, G., \& Bostanc1, T. G. (2016). The effects of one-day outdoor education on self- efficacy. Journal of human sciences, 13(3), 6098-6103. (Online), (https://doi.org/10.14687/jhs.v13i3.4296).

Zink, R., \& Boyes, M. (2006). The nature and scope of outdoor education in New Zealand schools. Australian journal of outdoor education, 10(1), 11-21. (Online), (https://doi.org/10.1007/bf03400826. 